\title{
The Effects of Cervus nippon on Two Key Ecological Drivers Controlling Populations of Plebejus argus on Heaths: Larval Food Sources and Mutualistic Ants
}

\author{
S. R. Woodley ${ }^{1}$ and A. Diaz ${ }^{1 *}$ \\ ${ }^{1}$ Department of Life and Environmental Sciences, Faculty of Science and Technology, Bournemouth \\ University, Talbot Campus, Fern Barrow, Poole, Dorset, BH12 5BB, UK.
}

Authors' contributions

Author SRW carried out all the data collection and analysis. He also wrote the first full draft of this manuscript including producing all the initial drafting of text and all the final figures. Author $A D$ supervised this project throughout, advising on experimental design, data analysis and project write up. She conducted the final drafting of this paper. All authors read and approved the final manuscript.

Article Information

DOI: $10.9734 / \mathrm{ACRI} / 2018 / 39140$ Editor(s):

(1) Ayona Jayadev, Professor, Department of Environmental Sciences, All Saints' College (Government Aided College Affiliated to University of Kerala), India.

(1) Manoel Fernando Demétrio, Brazil. (2) Hamit Ayberk, Istanbul University, Turkey. (3) Fatik Baran Mandal, Bankura Christian College, India (4) Virginia Meléndez Ramírez, Autonomous University of Yucatan, Mexico. Complete Peer review History: http://www.sciencedomain.org/review-history/23081

Original Research Article

Received $21^{\text {st }}$ November 2017

Accepted $30^{\text {th }}$ January 2018

Published $8^{\text {th }}$ February 2018

\begin{abstract}
This study investigated the effects of grazing by invasive sika deer, Cervus nippon on the abundance of the silver-studded blue butterfly Plebejus argus on a lowland heath system in the UK. Plebejus argus is a rare species whose UK stronghold is lowland heath, where it is dependent on a mutalistic relationship with species of Lasius niger ants. Cervus nippon is an invasive species but genetically and ecologically closely related to native red deer $C$. elaphus and so may have positive as well as negative ecological effects. This study examines the relationship between the incidence of $C$. nippon and the abundance of $P$. argus and tests the effect of deer i) directly via their impact on vegetation structure and composition, ii) indirectly their impact on the abundance of $L$. niger ants. Data were collected from 37 plots of heathland in Dorset, measuring $50 \mathrm{~m}$ by 50
\end{abstract}

${ }^{*}$ Corresponding author: Email: adiaz@bournemouth.ac.uk; 
$\mathrm{m}$ which were differentially grazed by deer. The abundance of $P$. argus was found to be significantly higher in areas with high incidence of $C$. nippon and the best predictor of butterfly abundance was the abundance of $L$. niger ants rather than the abundance of butterfly larval food plants. We conclude that this result provides evidence for an important indirect impact of grazing via manipulating habitat suitability for a key mutualistic species.

Keywords: Sika; grazing; Lasius ants; mutualist myrmecophile; silver-studded blue butterfly; lowland heathland.

\section{INTRODUCTION}

The silver-studded blue butterfly, Plebejus argus, is a conservation priority UK species [1,2] that is noted as vulnerable on the Red List of British butterflies using IUCN criteria [3]. It is at the northern edge of its global distribution range in the UK and is most often associated with heathland habitats although it also occurs on acid grasslands [4]. Its populations in Dorset and Hampshire, UK, are most often associated with wet or humid heath $[1,5,6]$. but also on dry heath after a fire or cut [5]. On lowland heath elsewhere across its UK range $P$. argus is associated with dry heath, such as in Suffolk [6] and West Sussex [7], and both dry and humid heath in Devon $[8,9]$. $P$. argus is one of the relatively few obligate myrmecophilous lycaenids in Europe [10], whereby its populations are strongly linked to ants. The butterfly can also be described as an oligo-symbiont as only two species of ant (Lasius niger and $L$. alienus) are used in its lifecycle [11]. The distributions of $P$. argus life stages are all associated with the distribution of $L$. niger or $L$. alienus; on heathland $P$. argus are always found next to or very near the nests of these ants [12]. Research based on GPS tracking of $P$. argus indicates that they fly slowly in winding circles round favourable sites while flying quickly across unfavourable sites [13].

Today, much European heathland has been lost to other land uses, and effective conservation of remaining fragments requires defoliation management to prevent successional change to woodland [14]. Current management techniques to halt succession on heathland include the use of domestic grazers to graze patches or whole areas of habitat [15-17] but burning [18] and cutting [19] are also used. Large herbivores have always played an important role in maintaining open landscapes through grazing, treading, dunging and urination [20,21] and it is known that deer can exert cascading effects by indirectly modifying the composition and physical structure of habitats $[22,23]$. There is also the potential for wild grazers to be utilised such as rabbits Oryctolagus cuniculus [24] and most particularly red deer Cervus elaphus [25-28]. Currently there is little information on the potential positive and negative roles of invasive sika deer $C$. nippon on heathlands and on the extent to whether sika deer can create favourable habitat for other plant and animal communities.

Cervus nippon are native to south-east Asia and were first introduced to Britain and Ireland in the late 1800's [29]. They are generalist feeders that can quickly change their behaviour to adapt to changes in environmental variables such as food availability [30]. As C. nippon become widely established they may assert an appreciable influence on an area's ecology [31]. There is no current information on the effects of $C$. nippon on thermophilous insects such as butterflies. Therefore, the resulting information shows the potential $C$. nippon has upon heathland sites to assist in the conservation of $P$. argus. This information could also be used generally to produce more effective management schemes on sites to benefit $P$. argus populations. Understanding the effect of grazing on the population size of $P$. argus requires knowledge of its impact on two key components: i) availability of food for larval and adult $P$. argus and ii) availability of Lasius ants. The aim of this study was to quantify and compare the changes that may be affecting $P$. argus either by changing food plant availability and suitability for larvae or adults, with those by affecting populations of Lasius ants.

\section{METHODS}

\subsection{Study Site}

The study site used was Arne Nature Reserve in south-east Dorset, UK and is managed by The Royal Society for the Protection of Birds (RSPB). Included in it are approximately 608 ha of grasslands, saltmarsh, woodland and heathlands, of which 158 ha is dry heath and 43 ha is wet heath. The only large mammal grazers 
on the site during the study period were $C$. nippon which during the time of this study occurred at a range of densities across the site with total population size being estimated as approximately 700 animals giving an average of more than one deer per ha which is extremely high (Royal Society for the Protection of Birds (RSPB) [32].

\subsection{Sampling Design}

A vegetation survey was carried out of all heathland at Arne during the summer of 2010 to establish the location of all main homogeneous areas of dry and wet heath of heathland at Arne. Areas were assigned as either 'dry heath' or 'wet heath' by using published guidelines for heath type [33], where wet heath contains Calluna vulgaris, Erica. tetralix, Sphagnum compactum and $S$. tenellum, and dry heath contains C.vulgaris, E. cinerea and Ulex minor. In order to assess the impact of $C$. nippon on $P$. argus, plots measuring $50 \mathrm{~m}$ by $50 \mathrm{~m}$ were established in random locations within homogeneous stands of vegetation across the wet heath habitat areas. A total of 22 wet heath and 20 dry heath plots were established (the number of plots was determined by the availability of areas of suitable habitat) (Fig. 1). Five of the dry heath plots (numbers 1, 3, 4, 7 and 10) were later discarded from the analysis as no $P$. argus were recorded here in three visits made within the middle of the flight period.

The abundance of $P$. argus on each plot was assessed by employing a transect walk over the flight period based on the line transect method $[34,35]$ but adapted into a circular transect walked at each site. Each circular transect had a radius of $20 \mathrm{~m}$, with one transect per plot, and each plot being walked along the same transect route three times within the middle of the $P$. argus flight period, with a mean value taken. This method is particularly effective because of the sedentary nature of $P$. argus.

All butterfly surveys were carried out when the weather was warm, sunny, and under calm conditions. $P$. argus abundance was recorded on each site a total of 10 times every two days during the middle of the flight period, from the last week of June to mid July.

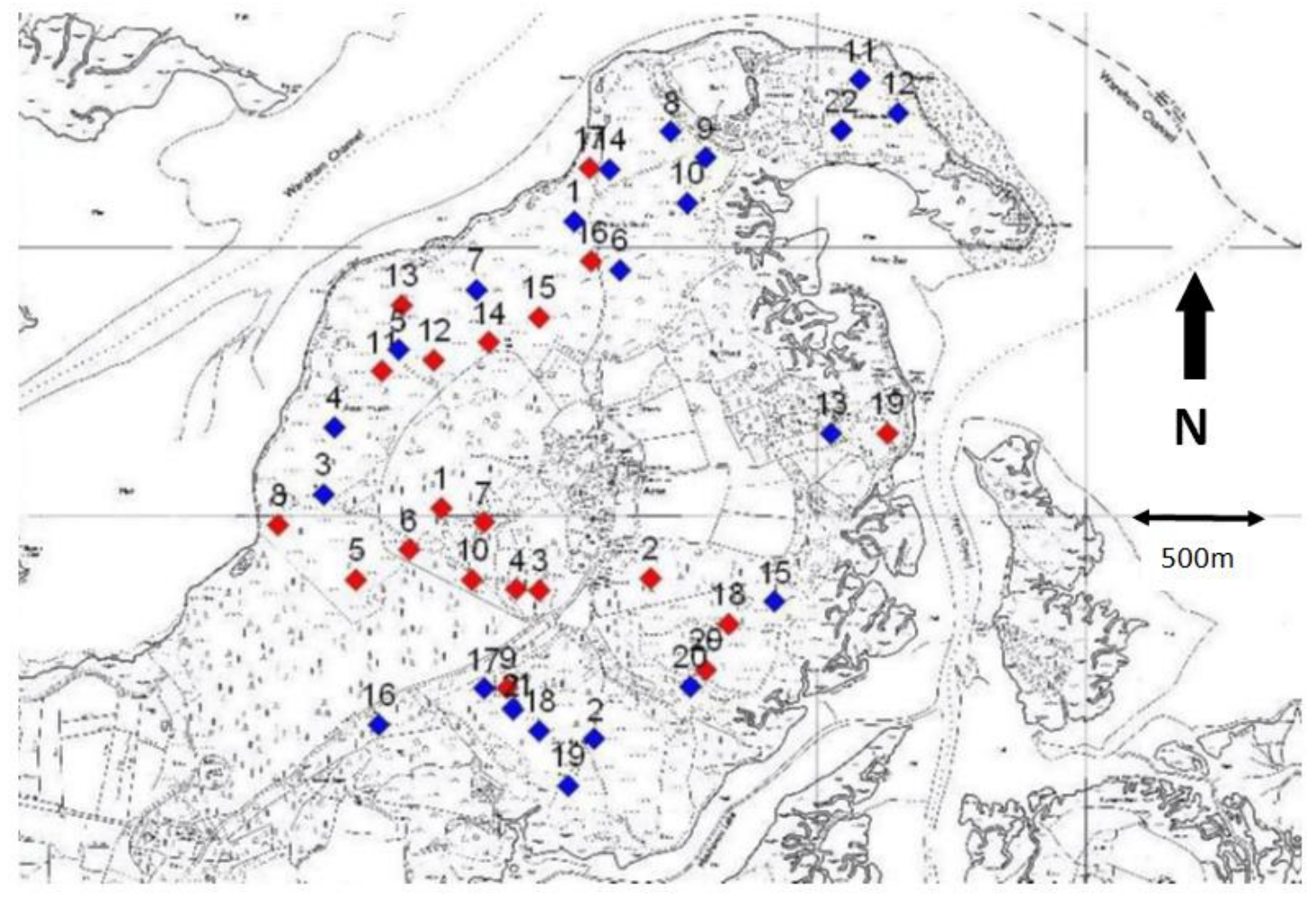

Fig. 1. The location of dry (red) and wet (blue) survey plots at Arne nature Reserve, Dorset, UK 
The incidence of sika deer on each plot was measured using the indirect index technique of recording standing crops of faecal pellets on each quadrat in midsummer [36-38]. Pellet counts were averaged from within three randomly located $5 \mathrm{~m}$ radius circular areas per site. All pellets present were counted.

Vegetation structure and plant community composition variables were recorded within each plot by using three randomly placed $2 \mathrm{~m} \times 2 \mathrm{~m}$ quadrats within each plot and averaging results. The vegetation structure variables recorded were: mean vegetation height, mean percentage cover of vegetation and vegetation volume. The last of these was estimated by visually recording the percentage occupancy of slices of the plot cube at $10 \mathrm{~cm}$ height intervals and using these to calculate volume occupancy per slice above ground level. These were summed to give a total vegetation volume estimate for each quadrat. Plant community composition was assessed by recording the percentage cover of each vascular plant species within each quadrat and then recording the mean for the plot. The abundance of $L$. niger and $L$. alienus on each plot was recorded using a baited transect method was employed using crumbled sweet digestive biscuits as bait (Bourn pers. comm.). For each plot three baits were placed within each of three randomly located $5 \mathrm{~m}$ radius sub-plots. Baits were left for 2-3 hrs before recording the number of ants.

\subsection{Data Analysis}

Data anlysis were performed using IBM SPSS Statistics version 9, Relationships between variables were examined using Pearson's Corretlation test. Data were tested for linearity using the curve fit function in SPSS. Two-tailed statistical tests were performed with significance $(P)$ assumed wherever $P<0.05$.

\section{RESULTS}

Sites varied in their incidence of deer, silver studded blue butterflies and ants (Fig. 2a, 2b and $2 c$ respectively). They also differed in important aspects of their vegetation structure particularly bare ground (Fig. 3a) mean vegetation height (Fig. 3b) and mean abundance of the main food plant Erica tetralix/Calluna vulgaris (Fig. 3c). At our study site at Arne $P$. argus was found on both wet and dry heath. However, it was much more abundant on wet heath that contains tall vegetation, which is largely dominated by $E$. tetralix, with patches of $M$. caerulea and some $C$. vulgaris. These sites also had high incidence of Lasius ants. The species of ant differed between dry and wet heath, on the dry heaths most ants were $L$. alienus whereas on the wet heath most were L. niger.

Tables 1 and 2 show the main results for plots on wet heath and dry heath, respectively. On wet heath habitat there is a significant, positive relationship between $C$. nippon (from pellet counts) and $P$. argus ( $r=0.457, P=0.033$ ), but this relationship is not significant for dry heath plots. Counterintuitively, a higher frequency of $C$. nippon (from pellet counts) correlated significantly with a higher mean vegetation height ( $r=0.512, P<0.05)$ on wet heath. On dry heath, a higher frequency of $C$. nippon correlates to a lower mean vegetation height $(r=-0.645, P$ $<0.01)$, with more bare ground $(r=0.639, P=$ 0.01). On wet heath $L$. niger was found more abundantly in taller vegetation $r=0.620, P=$ 0.002 , whereas on dry heath plots $L$. alienus was was found more in lower vegetation height, $r=$ $0.636 P=0.011$, with more bare ground $r=$ $0.752 P=0.001$.

Table 1. Correlations table for wet heath plots at Arne heathland $(n=22)$

\begin{tabular}{|c|c|c|c|c|c|c|}
\hline & \multicolumn{2}{|c|}{ C. nippon pellets } & \multicolumn{2}{|c|}{ L. niger abundance } & \multicolumn{2}{|c|}{$P$. argus abundance } \\
\hline & $\mathbf{r}$ & $P$ & $\mathbf{r}$ & $P$ & $\mathbf{r}$ & $P$ \\
\hline Vegetation volume $\left(\mathrm{m}^{3}\right)$ & -0.279 & 0.208 & -0.027 & 0.905 & -0.051 & 0.820 \\
\hline Vegetation height (cm) & $0.512^{*}$ & 0.015 & $0.620^{* *}$ & 0.002 & $0.475^{*}$ & 0.026 \\
\hline Erica tetralix (\% cover) & 0.129 & 0.568 & -0.048 & 0.833 & $0.472^{*}$ & 0.026 \\
\hline Molinia caerulea (\% cover) & 0.262 & 0.240 & 0.115 & 0.611 & 0.199 & 0.374 \\
\hline Bare ground (\%) & 0.364 & 0.096 & -0.049 & 0.830 & -0.203 & 0.365 \\
\hline C. nippon pellets $(\mathrm{n})$ & - & - & - & - & $0.457^{*}$ & 0.033 \\
\hline L. niger abundance $(\mathrm{n})$ & 0.327 & 0.137 & - & - & $0.607^{* *}$ & 0.003 \\
\hline
\end{tabular}



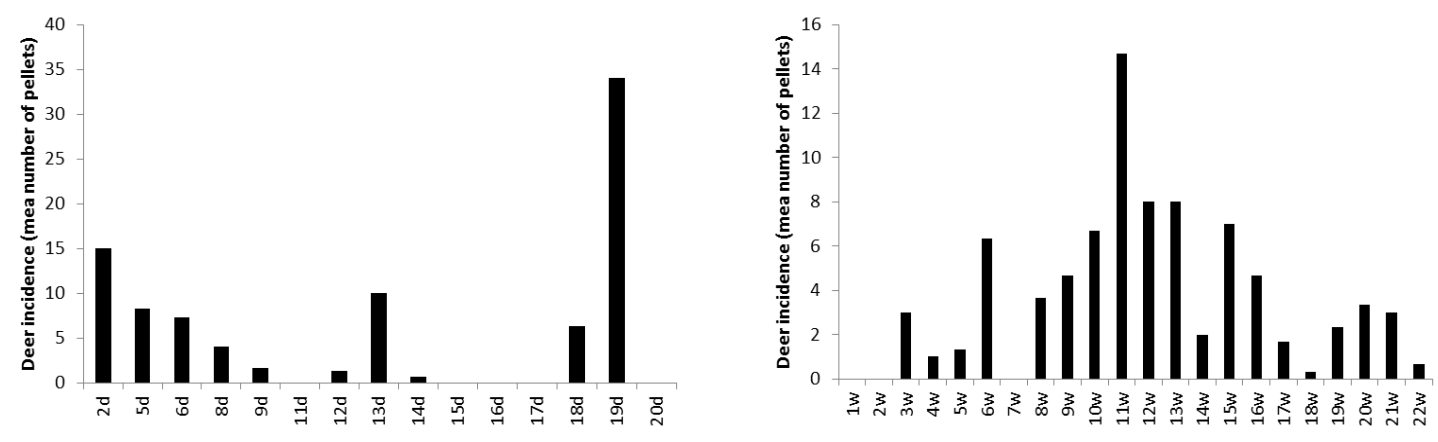

(a)
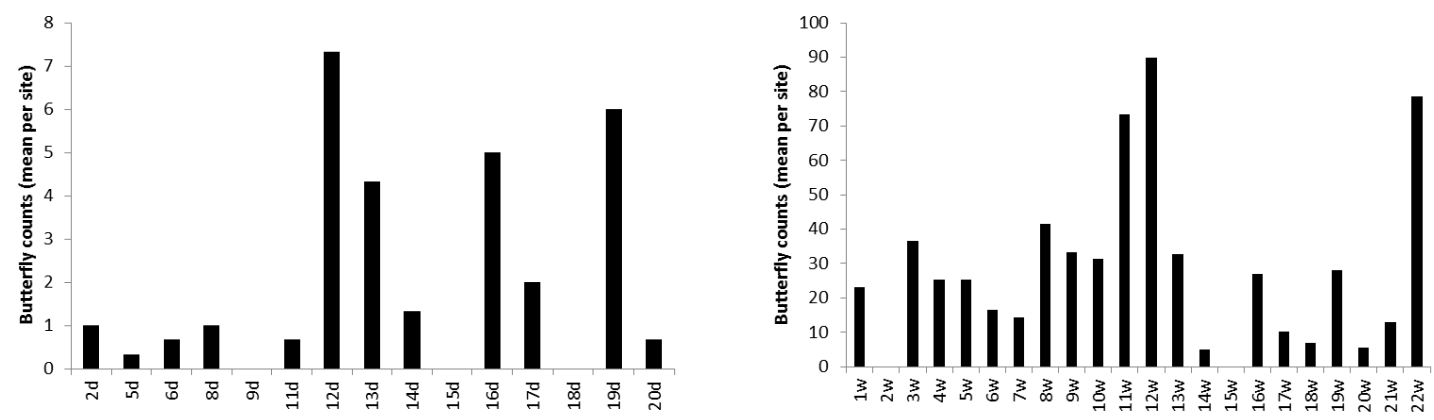

(b)
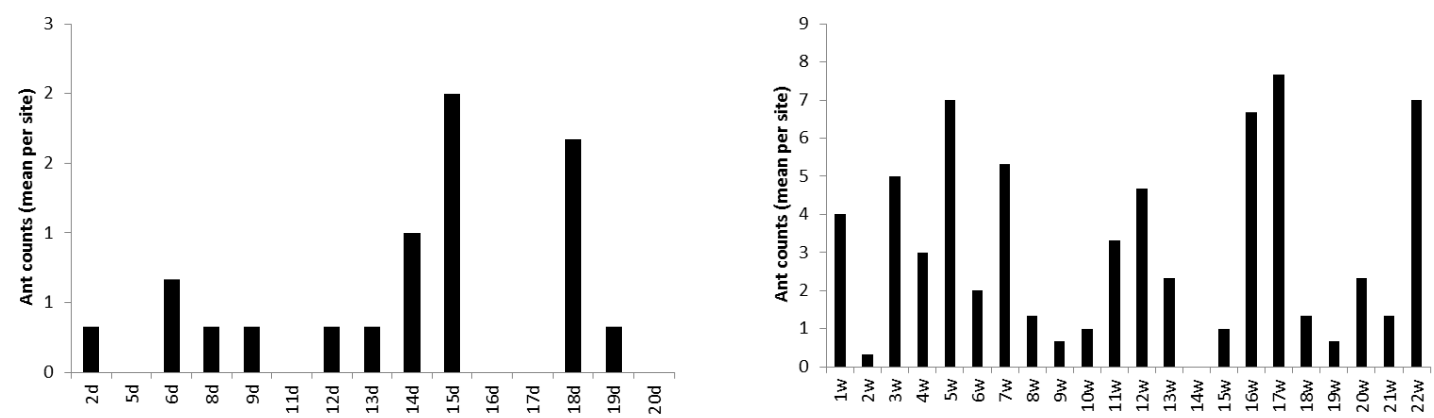

(c)

Wet Heaths

Dry Heaths

Fig. 2. Variation across the heaths in the mean incidence recorded for a) $C$. nippon deer, b) $P$. argus silver studded blue butterflies and c) Lasius spp. ants

In general wet heath plots with a taller vegetation height had more $P$. argus recorded $r=0.475, P<$ 0.05 , with a significant positive correlation between abundance of larval food sources and $P$. argus abundance, $r=0.472, P<0.05$. The opposite can be said of habitat use of $P$. argus on dry heath plots where the butterfly was found in areas of shorter vegetation $(r=-0.690 P=$ $0.004)$ and nearer to patches of bare ground ( $r=$
$0.744, P=0.001)$. The available of butterfly food plant here was largely dominated by Calluna with frequent patches of $E$. cinerea.

On both wet and dry heathland habitats there wass a strong positive correlation between Lasius ants and $P$. argus (wet heath plots $r=$ $0.607 P=0.003$, dry heath plots $r=0.835$, $P<0.001)$. 

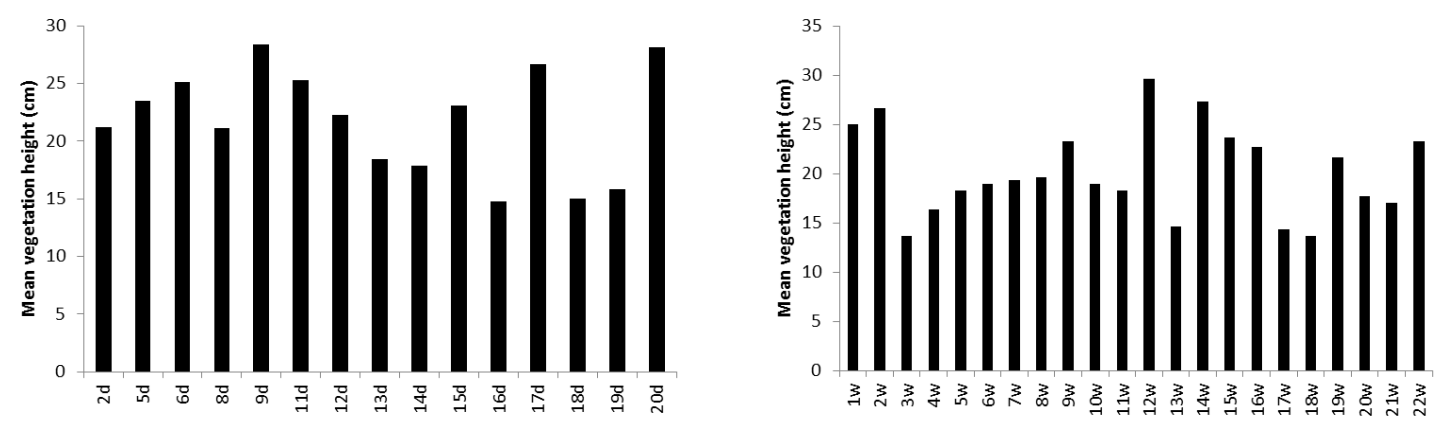

(a)
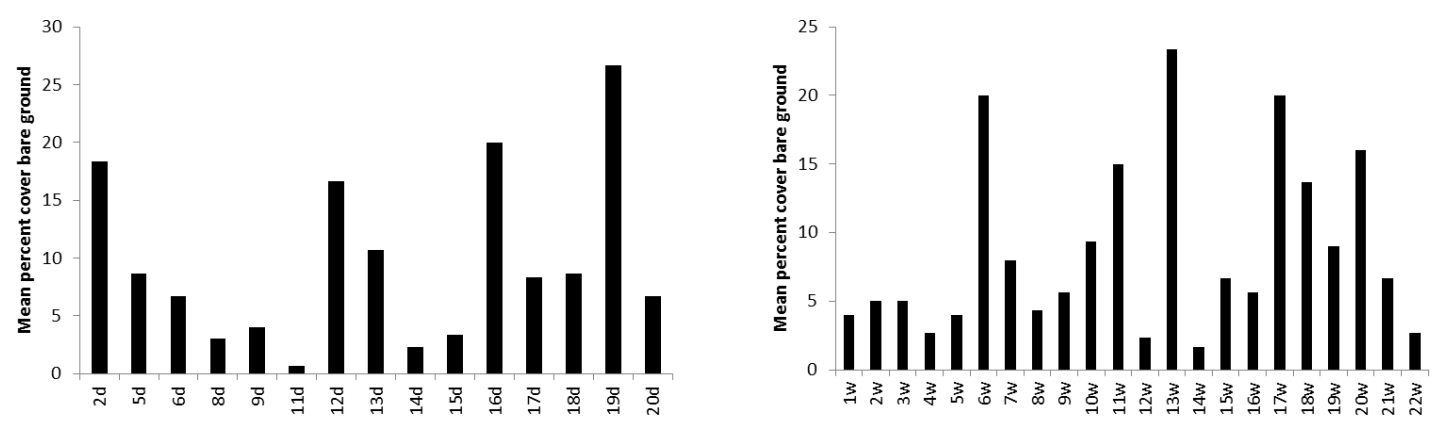

(b)
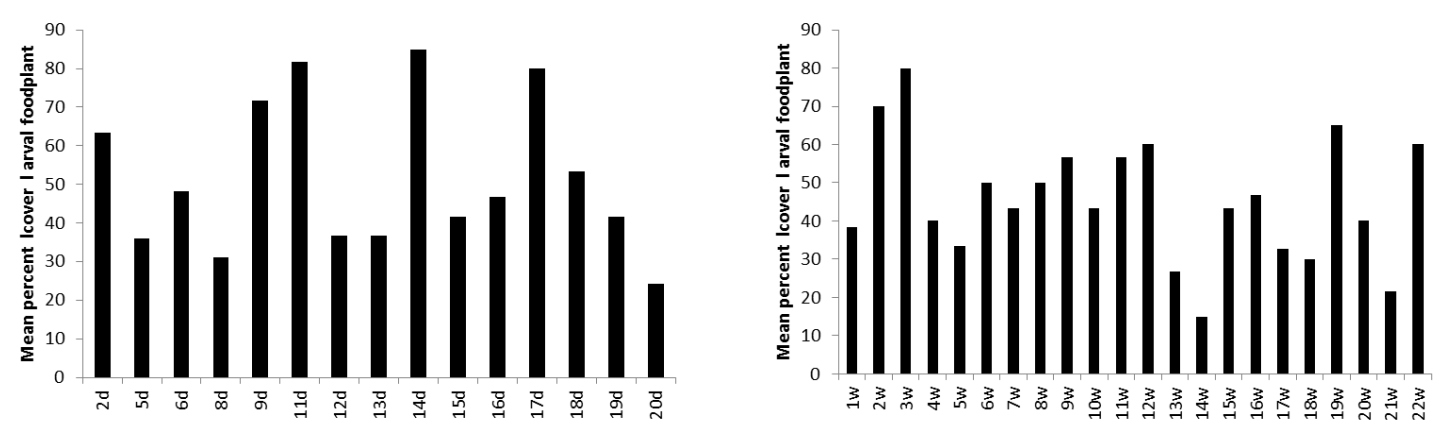

(c)

Wet Heaths

Dry Heaths

Fig. 3. Variation across the heaths in a) their \% cover of bear ground b) mean vegetation height c) mean abundance of Erica tetralix

Table 2. Correlations table for dry heath plots at Arne heathland $(n=15)$

\begin{tabular}{|c|c|c|c|c|c|c|}
\hline & \multicolumn{2}{|c|}{ C. nippon pellets } & \multicolumn{2}{|c|}{ L. alienus abundance } & \multicolumn{2}{|c|}{ P. argus abundance } \\
\hline & $\mathbf{r}$ & $P$ & $\mathbf{r}$ & $P$ & $\mathbf{r}$ & $P$ \\
\hline Vegetation volume $\left(\mathrm{m}^{3}\right)$ & -0.249 & 0.371 & -0.331 & 0.228 & -0.258 & 0.353 \\
\hline Vegetation height $(\mathrm{cm})$ & $-0.645^{* *}$ & 0.009 & $-0.636^{*}$ & 0.011 & $-0.690^{\star *}$ & 0.004 \\
\hline Erica cinerea (\% cover) & -0.114 & 0.343 & -0.015 & 0.958 & 0.105 & 0.710 \\
\hline Bare ground $(\%)$ & $0.639^{*}$ & 0.010 & $0.752^{\star *}$ & 0.001 & $0.744^{\star *}$ & 0.001 \\
\hline C. nippon pellets $(\mathrm{n})$ & - & - & - & - & 0.494 & 0.061 \\
\hline L. alienus abundance $(\mathrm{n})$ & 0.398 & 0.142 & - & - & $0.835^{\star \star *}$ & $<0.001$ \\
\hline
\end{tabular}




\section{DISCUSSION}

The aim of this study was to understand the impacts of $C$. nippon on the ecological drivers of $P$. argus at a site in Dorset where the butterfly exists on both wet and dry heath habitats. Overall our results show that grazing by $C$. nippon is associated with higher butterfly numbers, This agrees with findings from a study on heathlands in the Netherlands that $P$. argus was significantly more abundant under conditions of continous grazing by cattle compared to non grazing or summer-only grazing regimes [39].

Our results agree with previous work $[6,40]$ that on Dorset's lowland heathland it is areas of wet heath dominated by $E$. tetralix that preferred by $P$. argus. However, this may change in future as it is thought that $P$. argus occupies a broader niche on the warmer sites in the south of England [1] and specific warmer microclimates are not as necessary as they are for $P$. argus inhabiting areas further north of its range. At our study site at Arne $P$. argus is predominantly found on wet heath where the vegetation grows in tall patches dominated by $E$. tetralix with a high frequency of the ant $L$. niger. This association with taller wet heath has also been found for $P$. argus at its southern European limit where taller vegetation is preferred which reduces ground temperatures [12]. On dry heath $P$. argus occurred most abundantly where the vegetation is grazed short; the heather is often in pioneer stage with plenty of bare ground, and there is a high occurrence of the ant $L$. alienus.

Fig. 4 summarises the impact of $C$. nippon on $P$. argus at Arne. It illustrates all significant correlations found in this study incorporating direct and indirect relationships between the deer and the butterfly.

Our findings confirm the key important of habitat provision for Lasius ants. P. argus is a obligate mutualist myrmecophile meaning the larvae are herbivorous and are able to pass plant nutrients to their attendant ants. Mutualistic interactions minimize costs, yet optimize the benefits occurring from this association. There is a high degree of intimacy, but ants never depend on caterpillar secretions for nourishment, whereas butterfly larvae may depend on their association with ants. Mutualistic ants were shown to be more important than nectar source density in determining persistence of $P$. argus [10] and the frequency of nests of $L$. niger was by far the major predictor of $P$. argus abundance and presence-absence in a study in Spain [41]. The butterfly was shown to be absent from sites with low frequencies of $L$. niger or $L$. alienus,

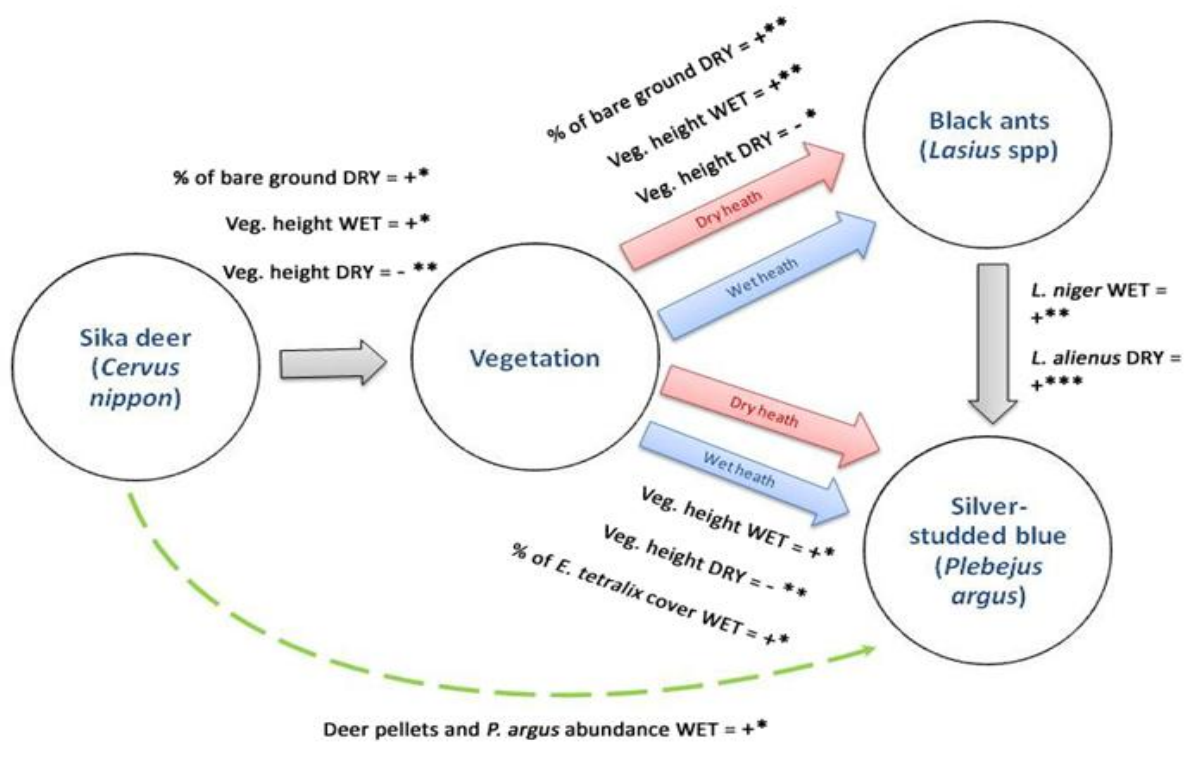

Fig. 4. Cervus nippon's relationship with $P$. argus and its impacts, showing significant correlations found in this research

Arrows indicate relationships, $W E T=$ wet heath, $D R Y=$ dry heath, $+/-=$ positive/negative correlation, ${ }^{*}=$ significance values where ${ }^{*} P<0.05,{ }^{* *} P<0.01,{ }^{* * *} P<0.001$ 
even though these sites contained abundant host plants and favourable microclimates [12]. The populations of $P$. argus found on heathland must therefore choose locations where the black Lasius ants inhabit amid their food plant. An increase in Lasius abundance equates to an increase in the abundance of $P$. argus. At Arne it may also be the case that Lasius ant densities are higher on wet heath sites than they are on dry heath.

Lasius niger is characteristic of low-lying wet areas, that are well vegetated, especially with the grass $M$. caerulea and the heath E. tetralix [42]. In a study in Spain [41] almost all L. niger nests are found at the bases of shrubs, because roots provide suitable sites for nest-building in the sandy soils. Although ants' nests were not studied by us it is a possibility that $L$. niger prefer to nest where clumps of $E$. tetralix or other equally suitable vegetation is growing for similar reasons. On dry heath areas the ant $L$. alienus prefers a warmer microclimate with a lower vegetation height and more bare ground [43]. The markedly different behaviour of $P$. argus inhabiting wet and dry heath is due to the habitat preference of the mutualistic ants on each heath type. The specific habitat preferences for each species depend on the vegetation type and cover and also to a certain degree elevation above sea level.

On wet heath plots we found areas with a taller vegetation height appeared to be preferred by $P$. argus. This agrees with findings from a coastal site in north Wales where population density was higher in shrubby areas where a substantial and significant bias in roosting and mating was found to occur and $P$. argus density was shown to be higher in the vicinity of shrubs which were also used for resting, basking, mate location and shelter $[44,45]$. At Arne gorse Ulex europaeus, bracken Pteridium aquilinum and grasses (mainly M. caerulea) were found in plots with a higher concentration of $P$. argus. $M$. caerulea is a highly digestible species [46] that flourishes under grazing and also possibly through dung deposition which may create high nutrient concentrations which certain grasses favour over dwarf shrubs [47]. On wet heaths $M$. caerulea can quickly fill gaps in open spaces in the vegetation cover or heather canopy. This could lead to taller mean heights as the grass grows taller to compete for light [48] but, M. caerulea only increased significantly when moisture content exceeded $60 \%$ [49].
The presence of $E$. tetralix is an important factor for $P$. argus populations as it is the predominant food plant on wet heath plots. The lightly and regularly grazed heathers still provide new shoots of growth on which the caterpillar can feed on [50]. Grazing on dry heath plots maintains a young green canopy where self shading from senescent leaves is reduced [51] thus enabling larvae to feed on suitable stems of the foodplant. On dry heath a short vegetation height with open patches of bare ground is preferred. These warmer microclimates may be favoured because they support high Lasius densities rather than because of any direct effect of temperature on the butterflies [12].

In summary, our study has shown that $C$. nippon graze areas of both wet and dry heathland and this is creating suitable habitat for both $L$. niger and $L$. alienus ant species. Grazing levels are not too high on either heath type despite high overall population densities of approximately 1 deer per ha. Our study agrees with previous findings [52] and show that this is because sika deer use dry heaths and other habitats more than wet heaths. The grazing by $C$. nippon creates open ground for ants and stimulates fresh growth of the larval food plant, whether that is E. tetralix (in wet heath plots), or C. vulgaris (in dry heath plots). Grazing also maintains a young green canopy where selfshading from senescent leaves is reduced. In doing so $C$. nippon creates a favourable environment for $P$. argus, therefore increasing not only the likelihood of the butterfly's presence but also its abundance.

On dry heath $C$. nippon grazing creates open bare ground and shorter vegetation with shorter stands of heather. On wet heath areas deer prefer plots with taller vegetation as they use such plots for harbourage as well as food sources. In particular we often witnessed young calves hidden in taller wet heath. The wet heath plots were, fortuitously, not over-dominated by $M$. caerulea and so the light grazing is sufficient to control this and create light gaps for Lasius ants and fresh growth of Erica tetralix. Care must however be taken with that $M$. caerulea does not become over-dominant on the sites as a result of lack of grazing (Chambers et al., 1999). Similarly, any grazing regime using a wild herbivore such as Sika deer will need population monitoring and management to ensure that dry heaths are not over-used so damaged. 


\section{CONCLUSION}

Overall our results indicate that grazing by $C$. nippon increased the abundance of $P$. argus and suggest that the causal relationship may be via C. nippon creating habitat suitability for Lassius ants more than by direct impacts on the larval food plants.

\section{ACKNOWLEDGEMENTS}

The authors thank Toby Branston and all the other staff at the RSPB Arne for their support of this research. We also thank Nigel Bourn from Butterfly Conservation for his guidance in the design of the data collection and advice on how to collect information on ant abundance.

\section{COMPETING INTERESTS}

The authors have declared that no competing interests exist.

\section{REFERENCES}

1. Asher $J$, Warren $M$, Fox $R$, Harding $P$, Jeffcoate $G$, Jeffcoate $S$. The millennium Atlas of butterflies in Britain and Ireland. Oxford University Press; 2001.

2. Fox R, Asher J, Brereton T, Roy D, Warren $M$. The state of butterflies in Britain and Ireland. Oxford: Pisces; 2006.

3. Fox R, Warren MS, Brereton TM. A new red list of british butterflies, species status 12. Peterborough: Joint Nature Conservation Committee; 2011.

4. Hodgson JA, Bennie JJ, Dale G, Longley $\mathrm{N}$, Wilson RJ, Thomas CD. Predicting microscale shifts in the distribution of the butterfly Plebejus argus at the northern edge of its range. Ecography. 2015;38(10):998-1005.

5. Thomas J, Webb N. The butterflies of dorset. Dorchester: Dorset Natural History and Archaeological Society; 1984.

6. Ravenscroft NOM, Warren MS. Species action plan: The silver-studded blue Plebejus argus. Wareham: Butterfly Conservation; 1996.

7. Crane, R. Iping and stedham local nature reserve. Report on the Silver-studded Blue butterfly. Report to LNR Management Committee, Sussex; 1995.

8. Read, M. The silver-studded blue conservation report. MSc Thesis. Imperial College; 1985.
9. Thomas JA, Rose RJ, Clarke RT, Thomas CD, Webb NR. Intraspecific variation in habitat availability among ectothermic animals near their climatic limits and their centres of range. Functional Ecology. 1999;13:55-64.

10. Seymour AS, Gutiérrez D, Jordana D. Dispersal of the lycaenid Plebejus argus in response to patches of its mutualist ant Lasius niger. Oikos. 2003;103:162-174.

11. Dennis RLH. A Resource-based Habitat View for Conservation. Butterflies in the British landscape. Chichester: WileyBlackwell; 2010.

12. Jordano, D., Rodriguez, J., Thomas, C.D. \& Fernandez Haeger, J. The distribution and density of a lycaenid butterfly in relationship to Lasius ants. Oecologia. 1992;91:439-446.

13. Fernández, P., Rodríguez, A., Obregón, R., de Haro, S., Jordano, D. and Fernández-Haeger, J. Fine scale movements of the butterfly Plebejus argus in a heterogeneous natural landscape as revealed by GPS Tracking. Journal of Insect Behavior. 2016;29(1):80-98.

14. Rose RJ, Webb NR, Clarke RT, Traynor $\mathrm{CH}$. Changes on heathlands in Dorset, England, between 1987 and 1996. Biological Conservation. 2000;93:117-125.

15. Bacon JC. Examples of current grazing management of lowland heathlands and implications for future policy. English Nature Research Report No. 271. Peterborough: English Nature; 1998.

16. Lake S, Bullock JM, Hartley S. Impacts of livestock grazing on lowland heathland in the UK. English Nature Research Report No. 422. Peterborough: English Nature; 2001.

17. Offer D, Edwards M, Edgar P. Grazing Heathland a guide to impact assessment for insects and reptiles. English Nature Research Report No. 497. Peterborough: English Nature; 2003.

18. Barker CG, Power SA, Bell JNB, Orme CDL. Effects of habitat management on heathland response to atmospheric nitrogen deposition. Biological Conservation. 2004;120:41-52.

19. Britton AJ, Marrs RH, Carey PD, Pakeman RJ. Comparison of techniques to increase Calluna vulgaris cover on heathland invaded by grasses in Breckland, south east England. Biological Conservation. 2000;95:227-232. 
20. van Wieren SE. The potential role of large herbivores in nature conservation and extensive land use in Europe. Biological Journal of the Linnean Society. 1995; 56:11-23.

21. Newton AC, Stewart GB, Myers G, Diaz A, Lake S, Bullock JM, Pullin AS. Impacts of grazing on lowland heathland in north-west Europe. Biological Conservation. 2009;142:935-947.

22. Fuller RJ. Responses of woodland birds to increasing numbers of deer: A review of evidence and mechanisms. Forestry. 2001;74(3):289-298.

23. Stewart AJA. The impact of deer on lowland woodland invertebrates: a review of the evidence and priorities for future research. Forestry. 2001;74(3):259-270.

24. Bullock JM, Pakeman RJ. Grazing of lowland heathland in England: management methods and their effects on heathland vegetation. Biological Conservation. 1996;79:1-13.

25. Clarke JL, Welch D, Gordon IJ. The influence of vegetation pattern on the grazing of heather moorland by red deer and sheep. II. The impact on heather. Journal of Applied Ecology. 1995;32:177186.

26. Hester AJ, Baillie GJ. Spatial and temporal patterns of heather use by sheep and red deer within natural heather/grass mosaics. Journal of Applied Ecology. 1998;35:772784.

27. Hester AJ, Gordon IJ, Baillie GJ, Tappin E. Foraging behaviour of sheep and red deer within natural heather/grass mosaics. Journal of Applied Ecology. 1999;36:133146.

28. Palmer SCF, Hester AJ. Predicting spatial variation in heather utilization by sheep and red deer within heather/grass mosaics. Journal of Applied Ecology. 2000;37:616631.

29. Putman RJ. Sika deer. London/Fordingbridge: The Mammal Society/British Deer Society; 2000.

30. Borkowski, J, Furubayashi K. Seasonal and diel variation in group size among Japanese sika deer in different habitats. Journal of Zoology. 1998;245:29-34.

31. Diaz A, Hughes S, Putman R, Mogg R, Bond JM. A genetic study of sika (Cervus nippon) in the New Forest and in the Purbeck region, southern England: is there evidence of recent or past hybridization with red deer (Cervus elaphus)?. Journal of Zoology. 2006;270:227-235.

32. Uzal AF. The interaction of Sika deer (Cervus nippon Temminck 1838) with lowland heath mosaics. Thesis, (PhD). Bournemouth University; 2010.

33. Chapman SB. The distribution and composition of hybrid populations of Erica ciliaris L. and Erica tetralix L. in Dorset. Journal of Ecology. 1975;63(3):809-823.

34. Pollard E. A method for assessing changes in abundance of butterflies. Biological Conservation. 1977;12:115-124.

35. Pollard E, Yates TJ. Monitoring butterflies for ecology and conservation. London: Chapman \& Hall; 1993.

36. Mitchell B, Rowe JJ, Ratcliffe PR, Hinge M. Defecation frequency in roe deer (Capreolus capreolus) in relation to the accumulation rates of faecal deposits. Journal of Zoology. 1985;207:1-7.

37. Marques FFC, Buckland ST, Goffin D, Dixon CE, Borchers DL, Mayle B, Peace AJ. Estimating deer abundance from line transect surveys of dung: sika deer in southern Scotland. Journal of Applied Ecology. 2001;38:349-363.

38. Acevedo P, Ruiz-Fons F, Vicente J, Reyes-Garcia AR, Alzaga V, Gortazar C. Estimating red deer abundance in a wide range of management situations in Mediterranean habitats. Journal of Zoology. 2008;276:37-47.

39. WallisDeVries MF, Noordijk J, Colijn EO, Smit JT, Veling K. Contrasting responses of insect communities to grazing intensity in lowland heathlands. Agriculture, Ecosystems \& Environment. 2016;234:7280.

40. Thomas JA. Rare species conservation: case studies of European butterflies. In The Scientific Management of Temperate Communities for Conservation: 149-197. Spellberg, I.F., Goldsmith, G.M. \& Morris, M.G. (Eds.). Oxford: Blackwell Scientific Publications; 1991.

41. Gutiérrez D, Fernandez P, Seymour AS, Jordano D. Habitat distribution models: are mutualist distributions good predictors of their associates. Ecological Applications. 2005;15(1):3-18.

42. Brian MV, Hibble J, Stradling DJ. Ant pattern and density in a southern English heath. Journal of Animal Ecology. 1965;34(3):545-555. 
43. Brian MV. Ant distribution in a southern English heath. Journal of Animal Ecology. 1964;33:451-461.

44. Dennis RLH. Just how important are structural elements as habitat components? Indications from a declining lycaenid butterfly with priority conservation status. Journal of Insect Conservation. 2004;8:37-45.

45. Dennis RLH, Sparks T. When is a habitat not a habitat? Dramatic resource use changes under differing weather conditions for the butterfly Plebejus argus. Biological Conservation. 2006;129:291-301.

46. Grant SA, Maxwell TJ. Hill vegetation and grazing by domesticated herbivores: the biology and definition of management options. In Ecological Change in the Uplands: 201-211. Usher, M.B. \& Thompson, D.B.A.(Eds). Oxford: Blackwell Scientific Publications; 1988.

47. Bakker JP, de Bie S, Dallinga JH, Tjaden $P$, de Vries $Y$. Sheep grazing as a management tool for heathland conservation and regeneration in the Netherlands. Journal of Applied Ecology. 1983;20:541-560.
48. Alonso I, Hartley SE. Effects of nutrient supply, light availability and herbivory on the growth of heather and three Competing grass species. Plant Ecology. 1998;137(2):203-212.

49. van Wieren SE. The management of populations of large mammals. In The Scientific Management of Temperate Communities for Conservation: 103-127. Spellberg, I.F., Goldsmith, G.M. \& Morris, M.G., (Eds.). Oxford: Blackwell Scientific Publications; 1991.

50. Thomas CD. Specializations and polyphagy of Plebejus argus (Lepidoptera: Lycaenidae) in North Wales. Ecological Entomology. 1985;10:325-340.

51. Morris JT, Jensen A. The carbon balance of grazed and non-grazed Spartina anglica saltmarshes at Skallingen, Denmark. Journal of Ecology. 1998;86:229-242.

52. Uzal A, Walls S, Stillman RA, Diaz A. Sika deer distribution and habitat selection: The influence of the availability and distribution of food, cover, and threats. Eur J Wildl Res. 2013;59:563-572.

(C) 2018 Woodley and Diaz; This is an Open Access article distributed under the terms of the Creative Commons Attribution License (http://creativecommons.org/licenses/by/4.0), which permits unrestricted use, distribution, and reproduction in any medium, provided the original work is properly cited.

Peer-review history:

The peer review history for this paper can be accessed here: http://www.sciencedomain.org/review-history/23081 